Historic, Archive Document

Do not assume content reflects current scientific knowledge, policies, or practices. 



\section{WHOLESALE IRIS BARGAINS}

For JULY DELIVERY ONLY we offer the following standard true-to-name Irises. We are making these low prices to reduce stocks quickly, as we are moving all of our Iris to our new farm. All divisions offered are clean and healthy and ready to go.

Variety

Color Per 100

Aurea-Yellow

Bluejay-Dark Blue $\$ 8.00$

C. A. Pfeiffer-Blue $\overline{\mathrm{S}}$, Violet F

Chester J. Hunt-Blue 4.00

Eldorado-Gold, Brown and Purple 8.00

Fairy-Bluish White _-_-__-_-_ $\mathbf{5 . 0 0}$

Her Majesty-Rose

5.00

James Boyd-Blue S, Violet F 4.00

Loreley-Yellow S, Plum F 5.00

Mary Garden-Variegated 8.00

Variety

Color

Per 100 Mad. Chereau-Lavender and White $\$ 4.00$ Monsignor-Deep Violet Mrs. H. Darwin-Blush White --_ 4.00 Powhatan-Pink Queen of May-Pink 7.00 - 5.00 Rhein Nixe-White S, Purple F _-_ 5.00 Rase Unique-Pink Sherwin Wright-Yellow 7.00

Wyomissing-Light Pink 5.00

Zanardelli-Lavender Blue 10.00 MIXFD IRIS-The above and many others. $\$ 3.00$ per $100 ; \$ 25.00$ per M. TERMS: $5 \%$ cash with order, $2 \%$ ten davs, net 30 days. 25 at 100 rate. No charge for packing. F. O. B. Dowagiac.

SPECIAL OFFER: Made to build new business. 10 each of the above twenty Iris (200 Divisions,) valued at $\$ 11.80$, for only $\$ 7.50$, prepaid to you. Order today.

\section{GEORGE W. HUNTER---Grower DOWAGIAC. MICH.}




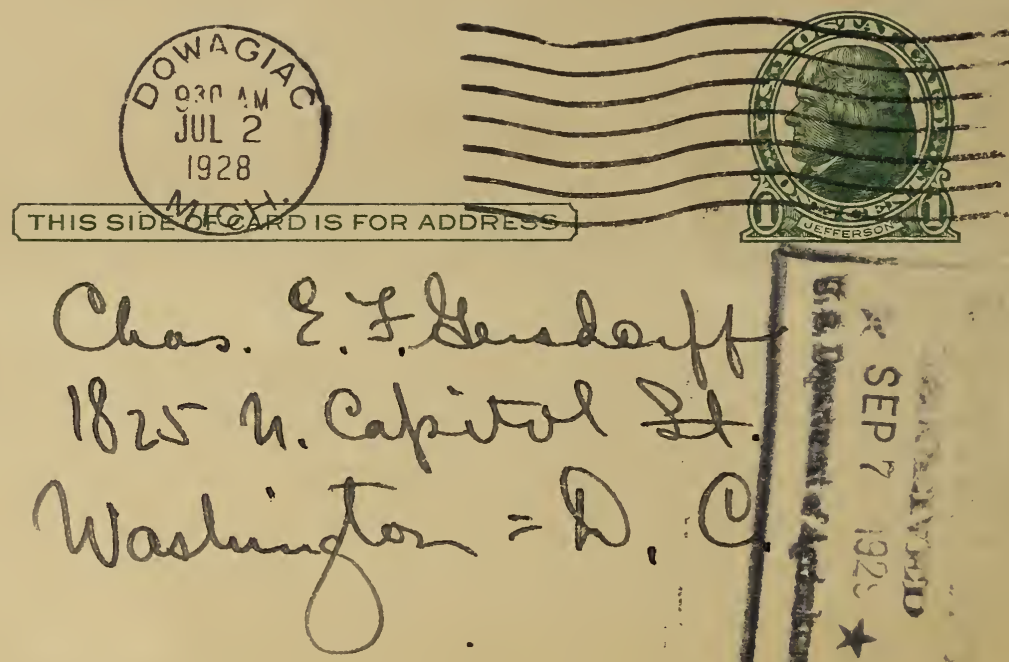

